\title{
A Group Decision-Making Model Based on Regression Method with Hesitant Fuzzy Preference Relations
}

\author{
Min Xue and Yifei Du \\ School of Management and Economics, University of Electronic Science and Technology of China, Chengdu 611731, China \\ Correspondence should be addressed to Yifei Du; yfd_666@163.com
}

Received 1 November 2016; Revised 17 November 2016; Accepted 8 December 2016; Published 3 January 2017

Academic Editor: Fazal M. Mahomed

Copyright (C) 2017 M. Xue and Y. Du. This is an open access article distributed under the Creative Commons Attribution License, which permits unrestricted use, distribution, and reproduction in any medium, provided the original work is properly cited.

\begin{abstract}
In recent years, the decision-making models with hesitant fuzzy preference relations (HFPRs) have received a lot of attention by some researchers. Meanwhile, the previous studies normally adopt normalization technical means to ensure the same number for all elements, which biases original information of decision-makers. In order to overcome this problem, in this paper, the multiplicative consistency of HFPRs is defined and the highest consistent reduced HFPRs are obtained by means of fuzzy linear programming method from given HFPRs. The proposed regression method eliminates the unreasonable information and retains the reasonable information from a given HFPR. In addition, the proposed method overcomes drawbacks of Zhu and Xu's regression method and is more simple and effective. On account of the obtained reduced HFPRs by the proposed regression method, a GDM model is established. Finally, a supplier selection problem was researched to present the effectiveness and pragmatism of the proposed approach, which proved that the method could offer beneficial insights into the GDM procedure.
\end{abstract}

\section{Introduction}

The Analytic Hierarchy Process (AHP) proposed by Saaty [1] is a currently common multiple criteria decision-making (MCDM) method. The preference relation is obtained by pairwise comparison matrices between alternatives over given criterion at a time, which is a major part of AHP. With the development of fuzzy mathematics, all kinds of preference relations were established, such as fuzzy preference relation (FPR) [2-5], linguistic preference relation [6$8]$, and intuitionistic fuzzy preference relation $[9,10]$. In the practical decision-making process, due to the complexity and uncertainty, it is difficult for decision-makers (DMs) to provide just a single term to evaluate two alternatives. To deal with this problem, Torra [11] proposed the hesitant fuzzy set, which allows DMs to consider several possible values at the same time to evaluate two methods. The hesitant fuzzy set complies with the cognitive characteristics of DMs, contains more influential information of DMs, and avoids the loss of information of DMs. From then on, the MCDM problems with hesitant fuzzy set have received close attention by some researchers [12-20]. Besides, all kinds of hesitant fuzzy aggregation operators also were proposed to integrate the preferences of experts in group decision-making (GDM) problem [18, 21, 22]. Furthermore, Xia and Xu [23] proposed the hesitant fuzzy preference relation (HFPR). The other two preference relations based on hesitant fuzzy set also were proposed: hesitant multiplicative preference relation (HMPR) [23-25] and hesitant fuzzy linguistic preference relation (HFLPR) [26-28].

The GDM models based on HFPR have gained wide attention in some literatures [16, 19, 23]. Xia and Xu [23] proposed the concept of HFPR and applied the GHFA, GHFWA, GHFG, and GHFWG operator to obtain the collective matric, respectively. Liao et al. [16] recommended the concept of multiplicative consistency of HFPR and carried out two iterative algorithms to improve the individual consistency level and consensus level of HFPR, respectively. Finally, a collective HFPR was obtained by integrating the individual HFPRs using AHFWA or AHFWG operator. Zhang et al. [19] proposed a GDM model simultaneously considering individual consistency and group consensus by means of automatic iteration based on the additive consistency of HFPR and applied the model to a supplier selection problem. However, Xia and Xu's [23] method does not consider the consistency and consensus of HFPR. In addition, Liao et al.s 
[16] method and Zhang et al.s [19] method add some new elements to HFPR in the process of normalization. As for the uncertainty of hesitant information, the above proposed methods should extract the reasonable information from the HFPR rather than trying to satisfy that all the comparison information should be perfectly consistent. At the same time, the cardinal consistency should be studied without utilizing the normalization process, because the normalization process biases original information [29]. Moreover, Zhu and $\mathrm{Xu}$ [30] introduced a regression method to obtain the highest consistent FPR in all possible FPRs from a given HFPR based on average estimated preference degree.

Based on the above motivations, in this paper, we are devoted to obtaining the FPR of highest consistent degree from given HFPR based on the multiplicative consistency of HFPR by means of fuzzy linear programming method. The obtained highest consistency FPR may be explained as the most reasonable information from a given HFPR, namely, a process of regression. Through two examples, it is demonstrated that the proposed regression method is valid and overcomes the drawback of Zhu and Xu's method [30]. Hence, the proposed GDM model based on fuzzy linear programming is believable. In the following, some new features of the proposed GDP model distinguished from the previous studies are summarized as follows:

(1) The proposed model avoids the bias for original information as much as possible, unlike the normalization method.

(2) The proposed model throws away some unreasonable information and retains the more relational information, which makes the result of GDM more rational.

(3) The calculation amount of the proposed model is reduced as it is based on the reduced HFPRs.

The rest of this paper is set up as follows. Section 2 reviews the definitions of FPRs and HFPRs. In Section 3, a fuzzy linear programming is proposed to seek for the FPR of the highest consistency level from a given HFPR based on multiplicative consistency of HFPR. In Section 4, a group decision-making model with HFPR based on regression method is established. In Section 5, a supplier selection problem is resolved by the proposed model. Some concluding remarks are given in Section 6 .

\section{Hesitant Fuzzy Preference Relations}

First of all, we review fuzzy preference relation (FPR) introduced by Tanino [31].

Definition 1 (see [31]). Let $P$ be a FPR for the set $A$ of alternatives $A=\left\{A_{1}, A_{2}, \ldots, A_{n}\right\}$, shown as follows:

$$
P=\left(p_{i j}\right)_{n \times n}=\left[\begin{array}{cccc}
0.5 & p_{12} & \cdots & p_{1 n} \\
p_{21} & 0.5 & \cdots & p_{2 n} \\
\vdots & \vdots & \ddots & \vdots \\
p_{n 1} & p_{n 2} & \cdots & 0.5
\end{array}\right] \text {, }
$$

where $p_{i j}$ indicates the degree of preference for alternative $A_{i}$ over $A_{j}, p_{i j} \in[0,1], p_{i j}=0.5$ denotes indifference between $A_{i}$ and $A_{j}, p_{i j}=1$ denotes $A_{i}$ is absolutely preferred to $A_{j}$, and $p_{i j}>0.5$ denotes $A_{i}$ is preferred to $A_{j}$, where $1 \leq i, j \leq n$.

Definition 2 (see [23]). Let $X=\left\{x_{1}, x_{2}, \ldots, x_{n}\right\}$ be a fixed set, and then a HFPR $H$ on $X$ is indicated as $H=\left(h_{i j}\right)_{n \times n} \subset X \times X$, where $h_{i j}=\left\{r_{i j}^{\sigma(l)} \mid l=1,2, \ldots, \# h_{i j}\right\}\left(\# h_{i j}\right.$ is the number of values in $h_{i j}$ ) is a hesitant fuzzy element, which denotes all the possible preference degree(s) of the objective $x_{i}$ over $x_{j}$. Moreover, $h_{i j}$ should satisfy the following conditions:

$$
\begin{aligned}
r_{i j}^{\sigma(l)}+r_{j i}^{\sigma\left(\# h_{i j}-l+1\right)} & =1, \\
r_{i i} & =\{0.5\}, \\
\# h_{i j}= & \# h_{j i}, \\
& \quad i, j=1,2, \ldots, n,
\end{aligned}
$$

where $r_{i j}^{\sigma(l)}$ is the $l$ th largest element in $h_{i j}$.

\section{A Regression for HFPR Using Fuzzy Linear Programming Method}

In this section, we will present a method to degenerate a HFPR to the highest consistent degree FPR by means of fuzzy linear programming, which we call a reduced HFPR. First of all, we propose the multiplicative consistency of HFPR based on multiplicative consistency of FPR. In the following, we review the concept of multiplicative consistency for FPR.

Definition 3 (see [32]). Let $P=\left(p_{i j}\right)_{n \times n}$ be a FPR. If $P$ satisfies the following conditions:

$$
p_{i j}=\frac{\omega_{i}}{\omega_{i}+\omega_{j}}, \quad i, j=1,2, \ldots, n,
$$

then $P$ is called a multiplicative consistent FPR, where $\omega=$ $\left(\omega_{1}, \omega_{2}, \ldots, \omega_{n}\right)^{T}$ is the priority weighting vector for $P=$ $\left(p_{i j}\right)_{n \times n}$ and $\sum_{i=1}^{n} \omega_{i}=1, \omega_{i} \geq 0, i=1,2, \ldots, n$.

Motivated by Definition 3, we establish the concept of multiplicative consistency of HFPR as follows.

Definition 4. Let $H=\left(h_{i j}\right)_{n \times n}$ be a HFPR. If $H$ satisfies the following conditions:

$$
\frac{\omega_{i}}{\omega_{i}+\omega_{j}}=h_{i j}^{(1)} \text { or } \cdots \text { or } h_{i j}^{\left(\# h_{i j}\right)}, \quad i, j=1,2, \ldots, n \text {, }
$$

then $H$ is called a multiplicative consistent HFPR, where $h_{i j}^{(l)}$ is the $l$ th element in $h_{i j}$, $\# h_{i j}$ is the number of $h_{i j}, \omega_{i}$ is the importance weight of the alternative $x_{i}$, and $\sum_{i=1}^{n} \omega_{i}=1, \omega_{i} \geq$ $0, i=1,2, \ldots, n$.

If a HFPR $H$ is not consistent, then there is no vector that satisfies (4). Meanwhile, it is difficult to satisfy the perfect consistency in real world, i.e., satisfying (4). Kacprzyk and 
Fedrizzi [33] proposed "Soft" consistency concept to express approximate consistency. Let $L_{i j}(\omega)=\left(h_{i j}-1\right) \omega_{i}+h_{i j} \omega_{j}$, and if $L_{i j}(\omega)=0$, then we say that the satisfaction degree of the priorities equals one. Otherwise, the satisfaction degree should reduce for some deviation. In what follows, we define the satisfaction degree related to the priorities by a membership function $m_{i j}(\omega)$ based on researches [34-37]:

$$
m_{i j}(\omega)= \begin{cases}1-\frac{L_{i j}(\omega)}{d}, & \text { if } L_{i j}(\omega) \geq 0 \\ 1+\frac{L_{i j}(\omega)}{d}, & \text { if } L_{i j}(\omega)<0\end{cases}
$$

where $d \geq 0$ is a deviation coefficient and it is obvious that $m_{i j}(\omega) \in(-\infty, 1]$. If $L_{i j}(\omega)=0$, then $m_{i j}(\omega)=1$, which indicates complete satisfaction; if $L_{i j}(\omega) \in[-d, d]$, then, $0 \leq$ $m_{i j}(\omega) \leq 1$, which indicates partial satisfaction; if $L_{i j}(\omega) \notin$ $[-d, d]$, then $m_{i j}(\omega)<0$, which indicates dissatisfaction.

Besides, let $Q^{n-1}=\left\{\left(\omega_{1}, \omega_{2}, \ldots, \omega_{n}\right) \mid \sum_{i=1}^{n} \omega_{i}=1, \omega_{i} \geq\right.$ $0\}$ be the simplex hyperplane. The overall satisfaction degree to the priority vector $\left(\omega_{1}, \omega_{2}, \ldots, \omega_{n}\right)^{T}$ can be defined as a membership function:

$$
m(\omega)=\min _{\omega \in Q^{n-1}}\left\{m_{i j}(\omega) \mid i, j=1,2, \ldots, n, i<j\right\}
$$

To obtain the highest satisfaction degree, we can maximize $m(\omega)$ as

$$
\lambda=\max \min _{\omega \in Q^{n-1}}\left\{m_{i j}(\omega) \mid i, j=1,2, \ldots, n, i<j\right\} .
$$

There exists at least one solution as $m(\omega)$ is a convex set, which has the maximum degree with membership $\lambda$. Model (7) can be transformed into model (8) based on a max-min optimization method [38] as follows:

$$
\begin{array}{ll}
\max & \lambda \\
\text { s.t. } & \lambda \leq m_{i j}(\omega) .
\end{array}
$$

By means of (5) and (8), a linear programming model can be obtained as follows:

$$
\begin{array}{ll}
\max & \lambda \\
\text { s.t. } & d \lambda+L_{i j}(\omega) \leq d, \\
& d \lambda-L_{i j}(\omega) \leq d, \\
& i, j=1,2, \ldots, n, i<j, \\
& \sum_{i=1}^{n} \omega_{i}=1, \quad \omega_{i} \geq 0, i=1,2, \ldots, n .
\end{array}
$$

Since $L_{i j}(\omega)=\left(h_{i j}-1\right) \omega_{i}+h_{i j} \omega_{j}$, model (9) can be rewritten as

$$
\begin{aligned}
\max \quad \lambda & \\
\text { s.t. } \quad d \lambda & -\left(1-\left(h_{i j}^{(1)} \text { or } \cdots \text { or } h_{i j}^{\left(\# h_{i j}\right)}\right)\right) \omega_{i} \\
& +\left(h_{i j}^{(1)} \text { or } \cdots \text { or } h_{i j}^{\left(\# h_{i j}\right)}\right) \omega_{j} \leq d, \\
d \lambda & +\left(1-\left(h_{i j}^{(1)} \text { or } \cdots \text { or } h_{i j}^{\left(\# h_{i j}\right)}\right)\right) \omega_{i} \\
& -\left(h_{i j}^{(1)} \text { or } \cdots \text { or } h_{i j}^{\left(\# h_{i j}\right)}\right) \omega_{j} \leq d, \\
i, j & =1,2, \ldots, n, i<j, \\
\sum_{i=1}^{n} \omega_{i} & =1, \quad \omega_{i} \geq 0, i=1,2, \ldots, n .
\end{aligned}
$$

In order to make model (10) easier to be understood, it can be turned into the following model:

$$
\begin{array}{ll}
\max & \lambda \\
\text { s.t. } \quad & d \lambda-\left(1-\sum_{l=1}^{\# h_{i j}} z_{i j}^{\sigma(l)} h_{i j}^{\sigma(l)}\right) \omega_{i} \\
& +\left(\sum_{l=1}^{\# h_{i j}} z_{i j}^{\sigma(l)} h_{i j}^{\sigma(l)}\right) \omega_{j} \leq d, \\
& d \lambda+\left(1-\sum_{l=1}^{\# h_{i j}} z_{i j}^{\sigma(l)} h_{i j}^{\sigma(l)}\right) \omega_{i} \\
& -\left(\sum_{l=1}^{\# h_{i j}} z_{i j}^{\sigma(l)} h_{i j}^{\sigma(l)}\right) \omega_{j} \leq d, \\
& i, j=1,2, \ldots, n, i<j, \\
\sum_{i=1}^{n} \omega_{i}=1, \quad \omega_{i} \geq 0, i=1,2, \ldots, n, \\
\# h_{i j} \\
\sum_{l=1} z_{i j}^{\sigma(l)}=1, \\
z_{i j}^{\sigma(l)}=0 \text { or } 1, i, j=1,2, \ldots, n, i<j, \\
l=1,2, \ldots h_{i j} .
\end{array}
$$

Based on the above discussion, it is worth noting that using model (11) is to find out the highest consistent property FPR within all possible FPRs from a given HFPR, namely, a reduced HFPR. 
Example 5. Assume a HFPR $H_{1}$ as follows:

$$
H_{1}=\left[\begin{array}{cccc}
\{0.5\} & \{0.4,0.5\} & \{0.6,0.7\} & \{0.6\} \\
\{0.6,0.5\} & \{0.5\} & \{0.8\} & \{0.4\} \\
\{0.4,0.3\} & \{0.2\} & \{0.5\} & \{0.1,0.2\} \\
\{0.4\} & \{0.6\} & \{0.9,0.8\} & \{0.5\}
\end{array}\right] .
$$

Set $d=1$, and let $\omega_{i}(i=1,2,3,4)$ be the priorities, and then, according to model (11), we obtain the following linear programming:

$$
\begin{aligned}
& \max \lambda \\
& \text { s.t. } \quad \lambda-\left(1-\left(z_{12}^{\sigma(1)} 0.4+z_{12}^{\sigma(2)} 0.5\right)\right) \omega_{1} \\
& +\left(z_{12}^{\sigma(1)} 0.4+z_{12}^{\sigma(2)} 0.5\right) \omega_{2} \leq 1, \\
& \lambda+\left(1-\left(z_{12}^{\sigma(1)} 0.4+z_{12}^{\sigma(2)} 0.5\right)\right) \omega_{1} \\
& -\left(z_{12}^{\sigma(1)} 0.4+z_{12}^{\sigma(2)} 0.5\right) \omega_{2} \leq 1, \\
& \lambda-\left(1-\left(z_{13}^{\sigma(1)} 0.6+z_{13}^{\sigma(2)} 0.7\right)\right) \omega_{1} \\
& +\left(z_{13}^{\sigma(1)} 0.6+z_{13}^{\sigma(2)} 0.7\right) \omega_{3} \leq 1, \\
& \lambda+\left(1-\left(z_{13}^{\sigma(1)} 0.6+z_{13}^{\sigma(2)} 0.7\right)\right) \omega_{1} \\
& -\left(z_{13}^{\sigma(1)} 0.6+z_{13}^{\sigma(2)} 0.7\right) \omega_{3} \leq 1, \\
& \lambda-(1-0.6) \omega_{1}+0.6 \omega_{4} \leq 1, \\
& \lambda+(1-0.6) \omega_{1}-0.6 \omega_{4} \leq 1, \\
& \lambda-(1-0.8) \omega_{2}+0.8 \omega_{3} \leq 1, \\
& \lambda+(1-0.8) \omega_{2}-0.8 \omega_{3} \leq 1, \\
& \lambda-(1-0.4) \omega_{2}+0.4 \omega_{4} \leq 1, \\
& \lambda+(1-0.4) \omega_{2}-0.4 \omega_{4} \leq 1, \\
& \lambda-\left(1-\left(z_{34}^{\sigma(1)} 0.1+z_{34}^{\sigma(2)} 0.2\right)\right) \omega_{3} \\
& +\left(z_{34}^{\sigma(1)} 0.1+z_{34}^{\sigma(2)} 0.2\right) \omega_{4} \leq 1, \\
& \lambda+\left(1-\left(z_{34}^{\sigma(1)} 0.1+z_{34}^{\sigma(2)} 0.2\right)\right) \omega_{3} \\
& -\left(z_{34}^{\sigma(1)} 0.1+z_{34}^{\sigma(2)} 0.2\right) \omega_{4} \leq 1, \\
& \sum_{i=1}^{n} \omega_{i}=1, \quad \omega_{i} \geq 0, \quad i=1,2,3,4, \\
& z_{12}^{\sigma(1)}+z_{12}^{\sigma(2)}=1, \\
& z_{13}^{\sigma(1)}+z_{13}^{\sigma(2)}=1, \\
& z_{34}^{\sigma(1)}+z_{34}^{\sigma(2)}=1 \\
& z_{12}^{\sigma(1)}, z_{12}^{\sigma(2)}, z_{13}^{\sigma(1)}, z_{13}^{\sigma(2)}, z_{34}^{\sigma(1)}, z_{34}^{\sigma(2)}=0 \text { or } 1 \text {. }
\end{aligned}
$$

TABLE 1: Results by model (11) with $H_{1}$.

\begin{tabular}{lcccccc}
\hline$d$ & $\lambda$ & $\omega_{1}$ & $\omega_{2}$ & $\omega_{3}$ & $\omega_{4}$ & The reduced HFPR \\
\hline 2 & 0.9804 & 0.3373 & 0.2588 & 0.1137 & 0.2902 & $R_{1}=R$ \\
1 & 0.9608 & 0.3373 & 0.2588 & 0.1137 & 0.2902 & $R_{2}=R$ \\
0.6 & 0.9346 & 0.3373 & 0.2588 & 0.1137 & 0.2902 & $R_{3}=R$ \\
0.1 & 0.6078 & 0.3373 & 0.2588 & 0.1137 & 0.2902 & $R_{4}=R$ \\
0.01 & -2.9216 & 0.3373 & 0.2588 & 0.1137 & 0.2902 & $R_{5}=R$ \\
\hline
\end{tabular}

We get $\lambda_{\max }=0.9608$ by MATLAB and the corresponding highest consistent FPR is as follows:

$$
R=\left[\begin{array}{llll}
0.5 & 0.5 & 0.7 & 0.6 \\
0.5 & 0.5 & 0.8 & 0.4 \\
0.3 & 0.2 & 0.5 & 0.2 \\
0.4 & 0.6 & 0.8 & 0.5
\end{array}\right]
$$

The obtained FPR is in agreement with Zhu and Xu's method [30]. It is showed that the proposed method is credible.

Remark 6. In model (11), the deviation parameters do not influence the priorities and reduced HFPRs obtained by our model but affect the membership $\lambda$. A large enough deviation parameter $d$ can guarantee that the intersection of all convex membership functions $m_{i j}(\omega)(i, j=1,2, \ldots, n)$ is not empty. Hence, we can get a positive $\lambda$ and find a feasible area on the simplex $[36,37]$. For $H_{1}$ in Example 5, by model (11) with different values for $d$, we obtain the results shown in Table 1. As can be seen from Table 1, it shows that the priorities of each objective and the reduced HFPRs remain unchanged and only change the membership $\lambda$ for the different values of $d$. Without loss of generality, we set $d=1$ in model (11).

Example 7. Assume a HFPR $\mathrm{H}_{2}$ as follows:

$$
\begin{aligned}
& H_{2} \\
& =\left[\begin{array}{cccc}
\{0.5\} & \{0.4,0.5\} & \{0.3,0.4\} & \{0.5,0.7\} \\
\{0.6,0.5\} & \{0.5\} & \{0.3\} & \{0.6,0.7,0.8\} \\
\{0.7,0.6\} & \{0.7\} & \{0.5\} & \{0.8\} \\
\{0.5,0.3\} & \{0.4,0.3,0.2\} & \{0.2\} & \{0.5\}
\end{array}\right] .
\end{aligned}
$$

We calculate model (11) by MATLAB and obtain $\lambda_{\max }=$ 0.9906, and the corresponding FPR is as follows:

$$
R=\left[\begin{array}{llll}
0.5 & 0.5 & 0.3 & 0.7 \\
0.5 & 0.5 & 0.3 & 0.7 \\
0.7 & 0.7 & 0.5 & 0.8 \\
0.3 & 0.3 & 0.2 & 0.5
\end{array}\right]
$$




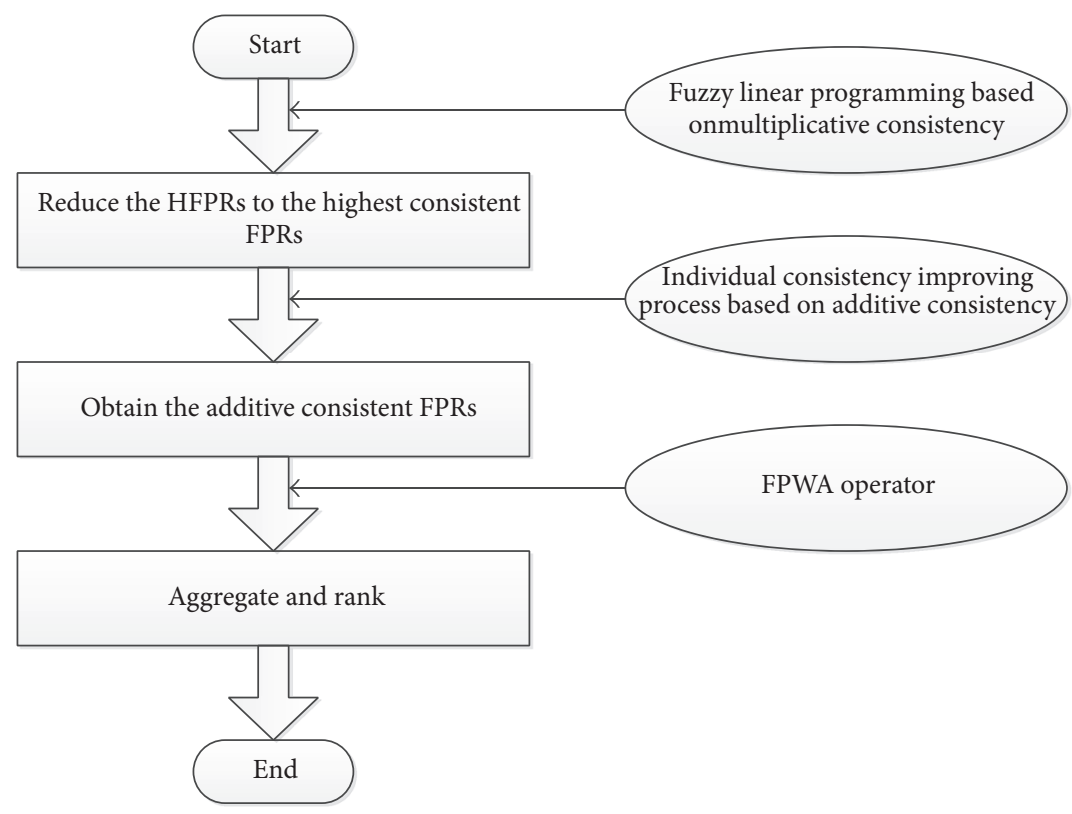

FIgURE 1: The framework of the GDM model.

Meanwhile, according to Zhu and Xu's method [30], the obtained highest consistent FPR is

$$
R^{\prime}=\left[\begin{array}{llll}
0.5 & 0.4 & 0.3 & 0.7 \\
0.6 & 0.5 & 0.3 & 0.7 \\
0.7 & 0.7 & 0.5 & 0.8 \\
0.3 & 0.3 & 0.2 & 0.5
\end{array}\right]
$$

By means of the additive consistency checking approach [39], we may obtain the consistency levels of the above two FPRs as follows: $\mathrm{CI}(R)=0.975>\mathrm{CI}\left(R^{\prime}\right)=0.958$. From the above analysis, it shows that the consistency level of the reduced HFPR by our method is higher than that by Zhu and Xu's method [30]. Therefore, the proposed regression method is more reasonable than Zhu and Xu's method.

\section{A Group Decision-Making Model Based on Regression Method with HFPR}

In this section, a group decision-making model based on regression method is established with HFPR. Assume that there are $n$ alternatives $x_{1}, x_{2}, \ldots, x_{n}$ and $m$ experts $E_{1}$, $E_{2}, \ldots, E_{m} . H^{q}(q=1,2, \ldots, m)$ indicates the HFPR given by expert $E_{q}(q=1,2, \ldots, m)$. The flow chart of the proposed GDM model is presented as Figure 1 and its procedure is specifically shown as follows.

Step 1. Reduce HFPRs $H^{q}(q=1,2, \ldots, m)$ to FPRs $p^{q}(q=$ $1,2, \ldots, m)$ by means of model (11), respectively.

Step 2. Establish the modified consistency matrix $\widetilde{P^{q}}$ based on $P^{q}(q=1,2, \ldots, m)$ by means of Chen et al.s [40] method as follows: (a) Firstly calculate $\overline{P^{q}}=\left(\overline{p_{i k}^{q}}\right)=\left((1 / 2 n) \sum_{j=1}^{n}\left(p_{i j}^{q}-\right.\right.$ $\left.\left.p_{j i}^{q}+p_{j k}^{q}-p_{k j}^{q}\right)+0.5\right)_{n \times n}, s_{i}^{q}=(1 / n) \sum_{j=1}^{n} \overline{p_{i j}^{q}}, m a_{q}=$ $\max \left(s_{i}^{q} \mid 1 \leq i \leq n\right), m i_{q}=\min \left(s_{i}^{q} \mid 1 \leq i \leq n\right)$, $b_{q}=1 /\left(2 \times \max \left(0.5,\left(M a_{q}-M i_{q}\right)\right)\right)$, and $c_{q}=1-$ $(2 / n(n-1)) \sum_{i=1}^{n} \sum_{k=1, k \neq i}^{n}\left|p_{i k}^{q}-\overline{p_{i k}^{q}}\right|$.

(b) Finally obtain $\widetilde{P^{q}}=\widetilde{\left(p_{i k}^{q}\right)_{n \times n}}=\left(\overline{p_{i k}^{q}} \times d_{q}+(1 / 2)(1-\right.$ $\left.\left.d_{q}\right)\right)_{n \times n}$, where $d_{q}=b_{q} \times c_{q}$.

Step 3. Construct the collective matrix $P^{c}$ based on experts' weights $\omega=\left(\omega_{1}, \omega_{2}, \ldots, \omega_{m}\right)^{T}$ by means of (18) (FPWA operator).

$$
\operatorname{FPWA}\left(p_{1}, p_{2}, \ldots, p_{m}\right)=\sum_{i=1}^{m}\left(\omega_{i} p_{i}\right)
$$

Step 4. It is computation of score function by means of (19) and ranking alternatives $x_{i}(i=1,2, \ldots, n)$.

$$
S\left(x_{i}\right)=\frac{2}{n(n-1)} \sum_{j=1, j \neq i}^{n} P_{i j}^{c} .
$$

If $S\left(x_{1}\right)>S\left(x_{2}\right)$, then $x_{1}>x_{2}$; if $S\left(x_{1}\right)=S\left(x_{2}\right)$, then $x_{1}=x_{2}$.

Step 5. End.

\section{Case Study: Supplier Selection Problem}

In recent decades, supply chain management (SCM) is a hot area of research [41-43]. The objective of SCM is to maximize total supply chain surplus based on the efficient process of raw materials, inventory, finished products, selling information, and capitals. It is supplier selection that affects the company's products competitive edge as well as the competitiveness of 
entire supply chain $[44,45]$. Ghodsypour and O'Brien [46] mentioned that the cost of raw materials and component parts occupies $70 \%$ of the product cost in manufacturing industries. Hence, selecting the correct supplier will result in increasing profitability, responding to customers' demands quickly, and improving competitiveness of the company in the market. In what follows, an application for supplier selection is presented.

Example 8 (see [19]). A solar company prepares to select a suitable supplier to purchase solar panels. In here, four potential suppliers are from USA, Germany, China, and Turkey, which are indicated as $x_{i}(i=1,2,3,4)$, respectively.

Four managers $m_{q}(q=1,2,3,4)$ (whose weighting vector is $\left.\omega=(0.1,0.5,0.3,0.1)^{T}\right)$ from different departments consist of group of decision-makers. They are asked to provide their assessed values for the four suppliers $x_{i}(i=$ $1,2,3,4)$ using the HFPRs. The managers $m_{q}(q=1,2,3,4)$ assessments are the HFPRs $H^{q}(q=1,2,3,4)$ as follows:

$$
H^{1}=\left[\begin{array}{cccc}
\{0.5\} & \{0.3\} & \{0.5,0.7\} & \{0.4\} \\
\{0.7\} & \{0.5\} & \{0.7,0.9\} & \{0.8\} \\
\{0.5,0.3\} & \{0.3,0.1\} & \{0.5\} & \{0.6,0.7\} \\
\{0.6\} & \{0.2\} & \{0.4,0.3\} & \{0.5\}
\end{array}\right],
$$

$H^{2}$

$$
=\left[\begin{array}{cccc}
\{0.5\} & \{0.3,0.5\} & \{0.1,0.2\} & \{0.6\} \\
\{0.7,0.5\} & \{0.5\} & \{0.7,0.8\} & \{0.1,0.3,0.5\} \\
\{0.9,0.8\} & \{0.3,0.2\} & \{0.5\} & \{0.5,0.6,0.7\} \\
\{0.4\} & \{0.9,0.7,0.5\} & \{0.5,0.4,0.3\} & \{0.5\}
\end{array}\right],
$$

$H^{3}$

$$
=\left[\begin{array}{cccc}
\{0.5\} & \{0.3,0.5\} & \{0.7\} & \{0.7,0.8\} \\
\{0.7,0.5\} & \{0.5\} & \{0.2,0.3,0.4\} & \{0.5,0.6\} \\
\{0.3\} & \{0.8,0.7,0.6\} & \{0.5\} & \{0.7,0.8,0.9\} \\
\{0.3,0.2\} & \{0.5,0.4\} & \{0.3,0.2,0.1\} & \{0.5\}
\end{array}\right],
$$

$H^{4}$

$$
=\left[\begin{array}{cccc}
\{0.5\} & \{0.4,0.5,0.6\} & \{0.3,0.4\} & \{0.5,0.7\} \\
\{0.6,0.5,0.4\} & \{0.5\} & \{0.3\} & \{0.6,0.7,0.8\} \\
\{0.7,0.6\} & \{0.7\} & \{0.5\} & \{0.8,0.9\} \\
\{0.5,0.3\} & \{0.4,0.3,0.2\} & \{0.2,0.1\} & \{0.5\}
\end{array}\right] .
$$

In what follows, a step-by-step procedure is given as follows.

Step 1. Reduce HFPRs $H^{q}(q=1,2,3,4)$ to FPRs $P^{q}(q=$ $1,2,3,4)$ by means of model (11), respectively.

$$
P^{1}=\left[\begin{array}{llll}
0.5 & 0.3 & 0.5 & 0.4 \\
0.7 & 0.5 & 0.7 & 0.8 \\
0.5 & 0.3 & 0.5 & 0.6 \\
0.6 & 0.2 & 0.4 & 0.5
\end{array}\right]
$$

$$
\begin{aligned}
P^{2} & =\left[\begin{array}{llll}
0.5 & 0.3 & 0.2 & 0.6 \\
0.7 & 0.5 & 0.7 & 0.5 \\
0.8 & 0.3 & 0.5 & 0.5 \\
0.4 & 0.5 & 0.5 & 0.5
\end{array}\right], \\
P^{3} & =\left[\begin{array}{llll}
0.5 & 0.5 & 0.7 & 0.7 \\
0.5 & 0.5 & 0.4 & 0.6 \\
0.3 & 0.6 & 0.5 & 0.7 \\
0.3 & 0.4 & 0.3 & 0.5
\end{array}\right], \\
P^{4} & =\left[\begin{array}{llll}
0.5 & 0.5 & 0.3 & 0.7 \\
0.5 & 0.5 & 0.3 & 0.6 \\
0.7 & 0.7 & 0.5 & 0.8 \\
0.3 & 0.4 & 0.2 & 0.5
\end{array}\right] .
\end{aligned}
$$

Step 2. Establish the modified consistency matrix $\widetilde{P^{q}}(q=$ $1,2,3,4)$ for every expert by means of Chen et al. method [40] as follows:

$$
\begin{aligned}
\widetilde{P^{1}} & =\left[\begin{array}{cccc}
0.5 & 0.2833 & 0.4567 & 0.5 \\
0.7167 & 0.5 & 0.5867 & 0.7167 \\
0.5433 & 0.4133 & 0.5 & 0.5433 \\
0.5 & 0.2833 & 0.4567 & 0.5
\end{array}\right], \\
\widetilde{P^{2}} & =\left[\begin{array}{cccc}
0.5 & 0.3467 & 0.4042 & 0.4425 \\
0.6533 & 0.5 & 0.5192 & 0.5959 \\
0.5958 & 0.4808 & 0.5 & 0.5384 \\
0.5575 & 0.4041 & 0.4616 & 0.5
\end{array}\right], \\
\widetilde{P^{3}} & =\left[\begin{array}{cccc}
0.5 & 0.6250 & 0.5625 & 0.6458 \\
0.3750 & 0.5 & 0.4375 & 0.5208 \\
0.4375 & 0.5625 & 0.5 & 0.5833 \\
0.3542 & 0.4792 & 0.4167 & 0.5
\end{array}\right], \\
\widetilde{P^{4}} & =\left[\begin{array}{cccc}
0.5 & 0.5233 & 0.3367 & 0.6400 \\
0.4767 & 0.5 & 0.3600 & 0.6167 \\
0.6633 & 0.6400 & 0.5 & 0.8033 \\
0.3600 & 0.3833 & 0.1967 & 0.5
\end{array}\right] .
\end{aligned}
$$

Step 3. Get the collective matrix for all experts based on expert's weights $\omega=(0.1,0.5,0.3,0.1)^{T}$ by means of $(18)$ :

$$
P^{c}=\left[\begin{array}{cccc}
0.5 & 0.4415 & 0.4502 & 0.5290 \\
0.5585 & 0.5 & 0.4855 & 0.5875 \\
0.5498 & 0.5145 & 0.5 & 0.5789 \\
0.4710 & 0.4125 & 0.4211 & 0.5
\end{array}\right]
$$


Step 4. It is ranking for alternatives by means of (19) as follows:

$S\left(x_{1}\right)=0.2368, S\left(x_{2}\right)=0.2719, S\left(x_{3}\right)=0.2739$, and $S\left(x_{4}\right)=0.2174$. Because $S\left(x_{3}\right)>S\left(x_{2}\right)>$ $S\left(x_{1}\right)>S\left(x_{4}\right)$, we obtain the ranking is $x_{3}>x_{2}>$ $x_{1}>x_{4}$. Hence, the best alternative is $x_{3}$ (i.e., China), which is the same as Zhang et al.s method [19]. In this case, it may be more convenient and tractable, since our method based on regression method has less computation quantity and is easier to understand than Zhang et al.s method. More importantly, the proposed method discards what is false and keeps what is genuine, which makes the result of decisionmaking more trusted.

\section{Conclusions}

In this paper, we proposed the multiplicative consistency of HFPR. Based on this, a fuzzy linear programming method has been presented to find out the highest consistent FPR from all possible FPRs, namely, a process of regression. In addition, through numerical examples, it has been showed that the reduced HFPR by the proposed method has the higher consistency level compared to Zhu and Xu's method. A step-by-step GDM procedure based on the reduced HFPRs has been concluded. Following the procedure, a supplier selection problem is worked out by means of the proposed model. With the help of the illustration, it is also depicted that the proposed GDM model is both practical and effective.

Meanwhile, the DMs frequently provide incomplete information in the process of real decision-making because of complicated decision environment, background knowledge, time pressure, and so forth. Hence, the GDM model with incomplete HFPR may be studied in the future work.

\section{Competing Interests}

The authors declare that there is no conflict of interests regarding the publication of this paper.

\section{Acknowledgments}

This research is partially supported by National Natural Science Foundation of China (nos. 71272131 and 71672021).

\section{References}

[1] T. L. Saaty, The analytic hierarchy process, McGraw-Hill International Book Co., New York, USA, 1980.

[2] S. A. Orlovsky, "Decision-making with a fuzzy preference relation," Fuzzy Sets and Systems, vol. 1, no. 3, pp. 155-167, 1978.

[3] F. Chiclana, F. Herrera, and E. Herrera-Viedma, "Integrating three representation models in fuzzy multipurpose decision making based on fuzzy preference relations," Fuzzy Sets and Systems. An International Journal in Information Science and Engineering, vol. 97, no. 1, pp. 33-48, 1998.

[4] E. Herrera-Viedma, F. Herrera, F. Chiclana, and M. Luque, "Some issues on consistency of fuzzy preference relations," European Journal of Operational Research, vol. 154, no. 1, pp. 98109, 2004.
[5] H.-B. Yan and T. Ma, "A group decision-making approach to uncertain quality function deployment based on fuzzy preference relation and fuzzy majority," European Journal of Operational Research, vol. 241, no. 3, pp. 815-829, 2015.

[6] Z. S. Xu, "Deviation measures of linguistic preference relations in group decision making," Omega, vol. 33, no. 3, pp. 249-254, 2005.

[7] Y. Dong, Y. Xu, and H. Li, "On consistency measures of linguistic preference relations," European Journal of Operational Research, vol. 189, no. 2, pp. 430-444, 2008.

[8] Y. Xu, H. Sun, and H. Wang, "Optimal consensus models for group decision making under linguistic preference relations," International Transactions in Operational Research, vol. 23, no. 6, pp. 1201-1228, 2016.

[9] E. Szmidt and J. Kacprzyk, "A consensus-reaching process under intuitionistic fuzzy preference relations," International Journal of Intelligent Systems, vol. 18, no. 7, pp. 837-852, 2003.

[10] H. Liao, Z. Xu, X.-J. Zeng, and D.-L. Xu, "An enhanced consensus reaching process in group decision making with intuitionistic fuzzy preference relations," Information Sciences, vol. 329, pp. 274-286, 2016.

[11] V. Torra, "Hesitant fuzzy sets," International Journal of Intelligent Systems, vol. 25, no. 6, pp. 529-539, 2010.

[12] R. M. Rodríguez, L. Martinez, and F. Herrera, "Hesitant fuzzy linguistic term sets for decision making," IEEE Transactions on Fuzzy Systems, vol. 20, no. 1, pp. 109-119, 2012.

[13] R. M. Rodríguez, L. Martínez, and F. Herrera, "A group decision making model dealing with comparative linguistic expressions based on hesitant fuzzy linguistic term sets," Information Sciences, vol. 241, pp. 28-42, 2013.

[14] D. Yu, W. Zhang, and Y. Xu, "Group decision making under hesitant fuzzy environment with application to personnel evaluation," Knowledge-Based Systems, vol. 52, pp. 1-10, 2013.

[15] S.-M. Chen and J.-A. Hong, "Multicriteria linguistic decision making based on hesitant fuzzy linguistic term sets and the aggregation of fuzzy sets," Information Sciences, vol. 286, pp. 6374, 2014.

[16] H. Liao, Z. Xu, and M. Xia, "Multiplicative consistency of hesitant fuzzy preference relation and its application in group decision making," International Journal of Information Technology and Decision Making, vol. 13, no. 1, pp. 47-76, 2014.

[17] C. Wei, N. Zhao, and X. Tang, "Operators and comparisons of hesitant fuzzy linguistic term sets," IEEE Transactions on Fuzzy Systems, vol. 22, no. 3, pp. 575-585, 2014.

[18] F. Meng, X. Chen, and Q. Zhang, "Induced generalized hesitant fuzzy Shapley hybrid operators and their application in multiattribute decision making," Applied Soft Computing Journal, vol. 28, pp. 599-607, 2015.

[19] Z. Zhang, C. Wang, and X. Tian, "A decision support model for group decision making with hesitant fuzzy preference relations," Knowledge-Based Systems, vol. 86, pp. 77-101, 2015.

[20] Y. J. Xu, L. Chen, R. M. Rodríguez, F. Herrera, and H. M. Wang, "Deriving the priority weights from incomplete hesitant fuzzy preference relations in group decision making," KnowledgeBased Systems, vol. 99, pp. 71-78, 2016.

[21] M. Xia and Z. Xu, "Hesitant fuzzy information aggregation in decision making," International Journal of Approximate Reasoning, vol. 52, no. 3, pp. 395-407, 2011.

[22] G. Wei, "Hesitant fuzzy prioritized operators and their application to multiple attribute decision making," Knowledge-Based Systems, vol. 31, pp. 176-182, 2012. 
[23] M. Xia and Z. Xu, "Managing hesitant information in GDM problems under fuzzy and multiplicative preference relations ," International Journal of Uncertainty, Fuzziness and KnowledgeBased Systems, vol. 21, no. 6, pp. 865-897, 2013.

[24] Z. M. Zhang and C. Wu, "Deriving the priority weights from hesitant multiplicative preference relations in group decision making," Applied Soft Computing, vol. 25, pp. 107-117, 2014.

[25] Y. He, Z. Xu, and J. Gu, "An approach to group decision making with hesitant information and its application in credit risk evaluation of enterprises," Applied Soft Computing, vol. 43, pp. 159-169, 2016.

[26] B. Zhu and Z. Xu, "Consistency measures for hesitant fuzzy linguistic preference relations," IEEE Transactions on Fuzzy Systems, vol. 22, no. 1, pp. 35-45, 2014.

[27] H. Wang and Z. Xu, "Some consistency measures of extended hesitant fuzzy linguistic preference relations," Information Sciences, vol. 297, pp. 316-331, 2015.

[28] Y. Dong, X. Chen, and F. Herrera, "Minimizing adjusted simple terms in the consensus reaching process with hesitant linguistic assessments in group decision making," Information Sciences, vol. 297, pp. 95-117, 2015.

[29] R. M. Rodríguez, B. Bedregal, H. Bustince et al., "A position and perspective analysis of hesitant fuzzy sets on information fusion in decision making. Towards high quality progress," Information Fusion, vol. 29, pp. 89-97, 2016.

[30] B. Zhu and Z. Xu, "Regression methods for hesitant fuzzy preference relations," Technological and Economic Development of Economy, vol. 19, pp. S214-S227, 2014.

[31] T. Tanino, "Fuzzy preference orderings in group decision making," Fuzzy Sets and Systems, vol. 12, no. 2, pp. 117-131, 1984.

[32] S. Lipovetsky and W. Michael Conklin, "Robust estimation of priorities in the AHP," European Journal of Operational Research, vol. 137, no. 1, pp. 110-122, 2002.

[33] J. Kacprzyk and M. Fedrizzi, "A "soft" measure of consensus in the setting of partial (fuzzy) preferences," European Journal of Operational Research, vol. 34, no. 3, pp. 316-325, 1988.

[34] L. Mikhailov, "A fuzzy programming method for deriving priorities in the analytic hierarchy process," Journal of the Operational Research Society, vol. 51, no. 3, pp. 341-349, 2000.

[35] L. Mikhailov, "A fuzzy approach to deriving priorities from interval pairwise comparison judgements," European Journal of Operational Research, vol. 159, no. 3, pp. 687-704, 2004.

[36] B. Zhu and Z. Xu, "A fuzzy linear programming method for group decision making with additive reciprocal fuzzy preference relations," Fuzzy Sets and Systems, vol. 246, pp. 19-33, 2014.

[37] B. Zhu and Z. Xu, "Analytic hierarchy process-hesitant group decision making," European Journal of Operational Research, vol. 239, no. 3, pp. 794-801, 2014.

[38] R. E. Bellman and L. A. Zadeh, "Decision-making in a fuzzy environment," Management Science. Journal of the Institute of Management Science. Application and Theory Series, vol. 17, pp. B141-B164, 1970/71.

[39] F. Meng and X. Chen, "A new method for group decision making with incomplete fuzzy preference relations," KnowledgeBased Systems, vol. 73, pp. 111-123, 2015.

[40] S.-M. Chen, T.-E. Lin, and L.-W. Lee, “Group decision making using incomplete fuzzy preference relations based on the additive consistency and the order consistency," Information Sciences, vol. 259, pp. 1-15, 2014.

[41] C.-H. Chiu, T.-M. Choi, and C. S. Tang, "Price, rebate, and returns supply contracts for coordinating supply chains with price-dependent demands," Production and Operations Management, vol. 20, no. 1, pp. 81-91, 2011.

[42] X. Chen and Q. Zhou, "Loss-averse retailer's optimal ordering policies for perishable products with customer returns," Mathematical Problems in Engineering, vol. 2014, Article ID 831796, 5 pages, 2014.

[43] N. Wan and X. Chen, "Bilateral coordination strategy of supply chain with bidirectional option contracts under inflation," Mathematical Problems in Engineering, vol. 2015, Article ID 369132, 16 pages, 2015.

[44] W. Ho, X. Xu, and P. K. Dey, "Multi-criteria decision making approaches for supplier evaluation and selection: a literature review," European Journal of Operational Research, vol. 202, no. 1, pp. 16-24, 2010.

[45] K. S. Moghaddam, "Fuzzy multi-objective model for supplier selection and order allocation in reverse logistics systems under supply and demand uncertainty," Expert Systems with Applications, vol. 42, no. 15-16, pp. 6237-6254, 2015.

[46] S. H. Ghodsypour and C. O’Brien, "A decision support system for supplier selection using an integrated analytic hierarchy process and linear programming," International Journal of Production Economics, vol. 56-57, pp. 199-212, 1998. 


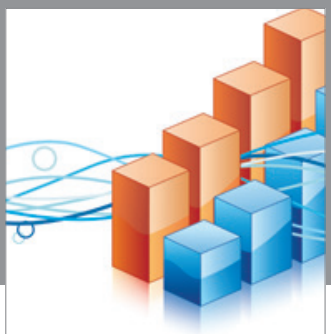

Advances in

Operations Research

vatem alat4

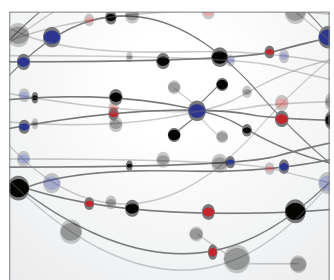

\section{The Scientific} World Journal
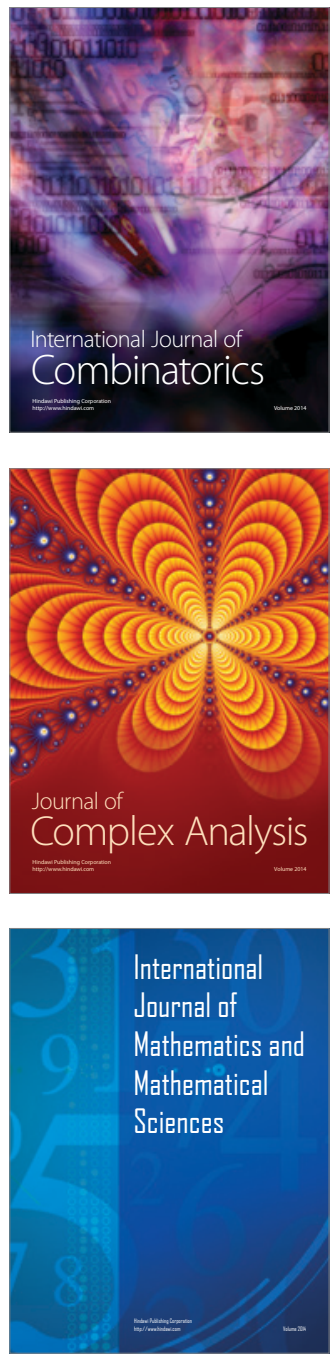
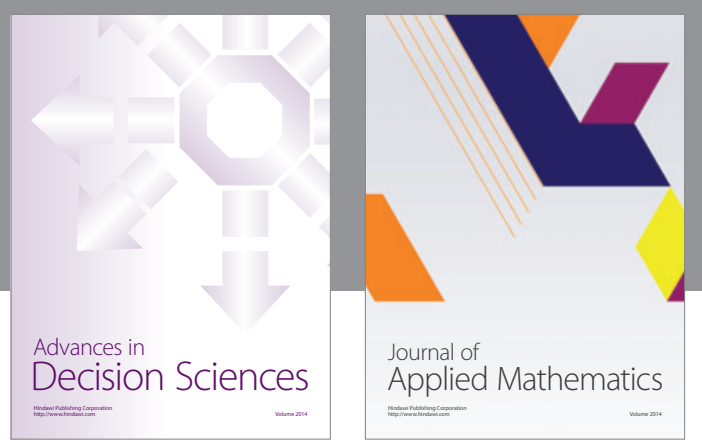

Algebra

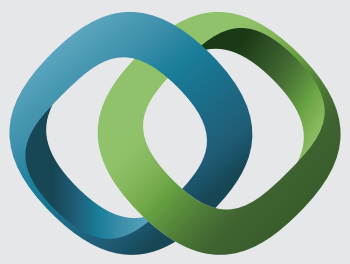

\section{Hindawi}

Submit your manuscripts at

https://www.hindawi.com
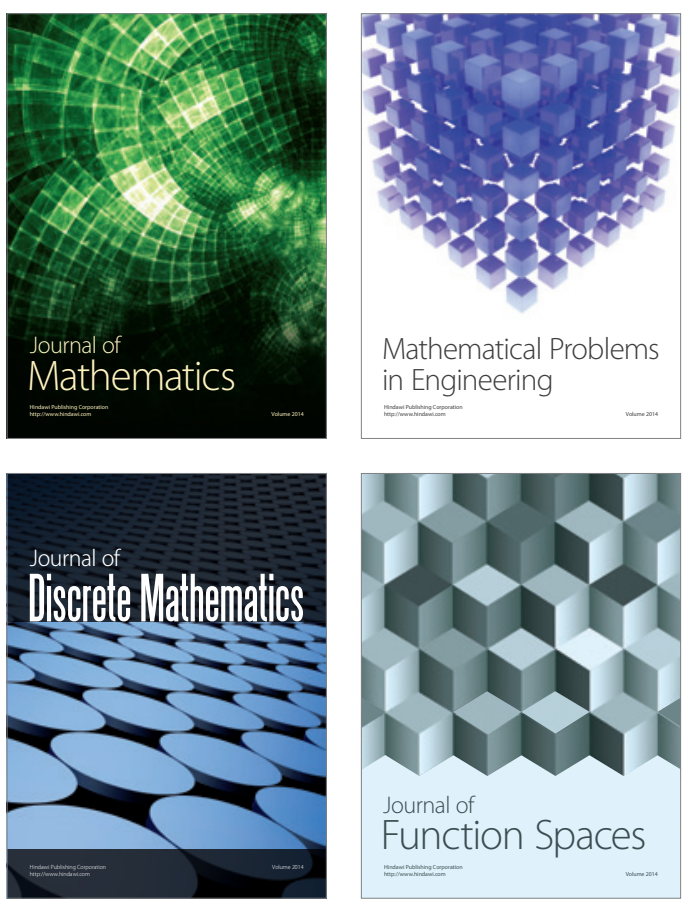

Mathematical Problems in Engineering
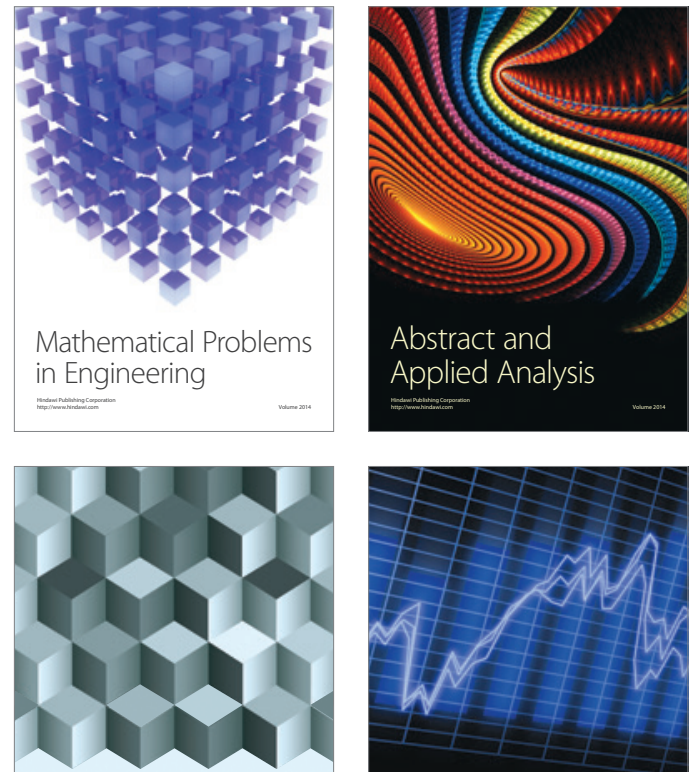

Journal of

Function Spaces

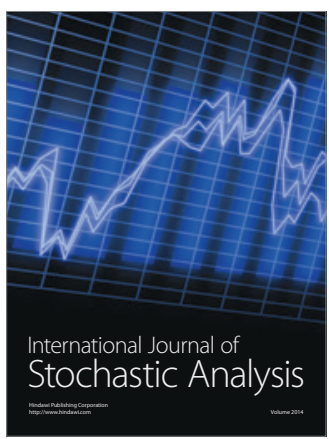

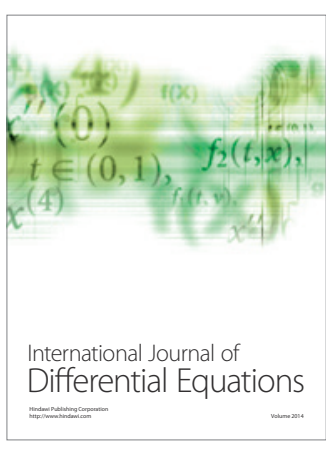
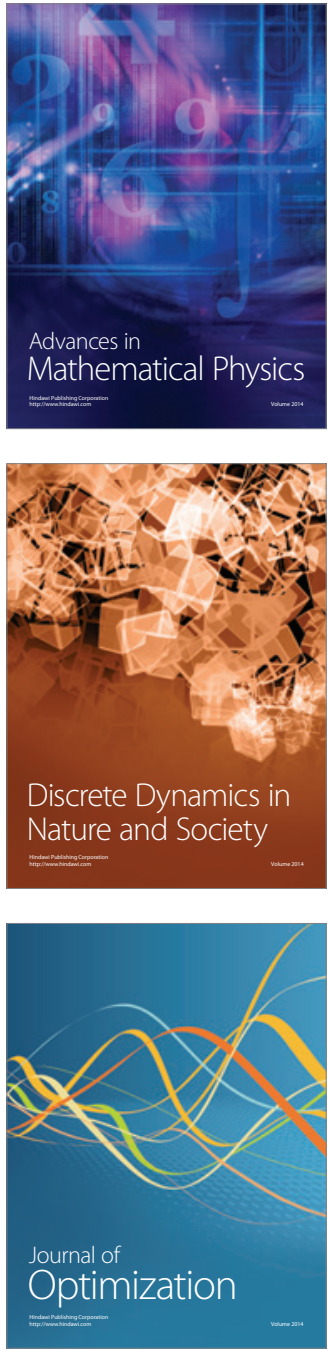